\title{
The Reactant Concentration Simulation at Catalyst Membrane Interface of a MICRO PEM Fuel Cell
}

\author{
Sean Goudy, S. O. Bade Shrestha, Iskender Sahin \\ Department of Mechanical and Aeronautical Engineering, \\ Western Michigan University, Kalamazoo, Michigan, USA \\ Corresponding email: bade.shrestha@wmich.edu
}

\begin{abstract}
Modeling is increasingly widely used to optimization, improvement and cost reduction efforts of the fuel cell technology. Although there are many computational models in literature that describe the behavior of Polymer Electrolyte Membrane (PEM) fuel cell, there is a only few models that simulates the catalyst surface concentration of reactant gases at the catalyst-membrane layer inteface. A modeling of a PEM fuel cell is presented to determine both the bulk reactant concentrations and the catalyst surface concentrations at the catalyst layer-membrane layer interface. The results suggest that the reactant deficiencies experienced at high current densities are localized to the catalyst surface. However, the bulk concentration of reactant is not zero, and, in most cases, the bulk concentration of the reactant gases is significantly greater than zero. In actuality, it is the catalyst surface, which is being depleted of reactant, and, at the limiting current density, the surface concentrations of reactant gases are zero. This treatment develops explicitly link between the fuel cell overpotentials and the movement of reactants.
\end{abstract}

\section{Introduction}

Modeling has to play increasingly bigger role in optimizing performance, improving efficiency and reducing cost of fuel cells as we go forward towards the more sustainable and renewable energy economics of future. Hydrogen energy economics not only provide the benign sustainable and renewable way of energy production and uses for foreseeable future, but also resolve the global warming and climate change, energy dependence and depletion of fossil fuel concerns for ever. Of course, hydrogen is an energy carrier which has to be produced and used in renewable and sustainable way to inherit all the benefits it can provide. Fuel cell technology is a major component of the hydrogen energy economics, that will convert energy of hydrogen bond to electricity at almost double of the efficiency of the current internal combustion engines. Polymer electrolyte membrane (PEM) fuel cells are considered as a prime motive power alternative for vehicular application that will replaced the IC engine dominance in this sector today.

A PEM fuel cells is a device that convert hydrogen gas $\left(\mathrm{H}_{2}\right)$ and oxygen gas $\left(\mathrm{O}_{2}\right)$ into electrical energy releasing water and heat as the by-product of the electrochemical process in the presence of catalyst as:

$$
2 \mathrm{H}_{2}+\mathrm{O}_{2} \stackrel{P t}{\longrightarrow} 2 \mathrm{H}_{2} \mathrm{O}+\text { Energy }
$$

A PEM fuel cell is divided into an anode and a cathode, which are separated by a polymer membrane as shown schematically in Figure 1. 


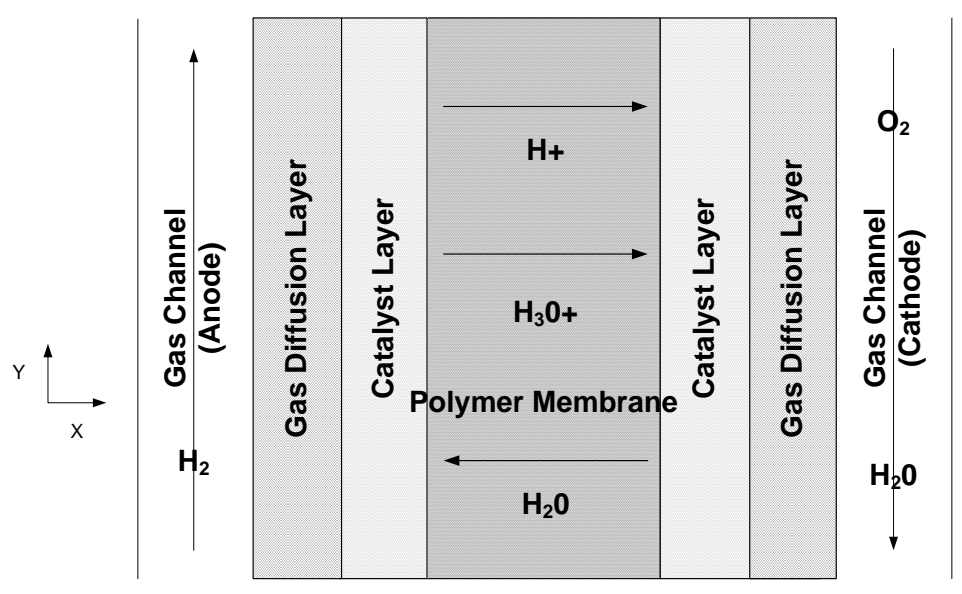

Figure 1: PEM Fuel Cell Schematic

At the anode, hydrogen gas is oxidized liberating two hydrogen ions and two electrons as:

$$
\mathrm{H}_{2} \stackrel{\mathrm{Pt}}{\longrightarrow} 2 \mathrm{H}^{+}+2 e^{-}
$$

At the cathode, oxygen gas is reduced and reacts electrochemically with the hydrogen ions and the electrons as follows:

$$
\mathrm{O}_{2}+4 \mathrm{H}^{+}+4 e^{-} \stackrel{P t}{\longrightarrow} 2 \mathrm{H}_{2} \mathrm{O}
$$

Fundamentally, a fuel cell is a device used to convert the energy stored within the covalent bonds of hydrogen gas molecules into electrical energy [1]. The only by-products of this electrochemical process are water and heat.

The most of the models implicitly assumed that the hydrogen and oxygen concentrations at the catalyst layer-membrane interfaces were zero; however, our data show that, although the concentrations of the reactant gases are reduced compared to the gas channel conditions, the hydrogen concentration and the oxygen concentration at the catalyst layer-membrane interfaces at both the anode and the cathode are not zero.

The objective of this study was to develop a functioning one-dimensional (1-D) computational model of a PEM fuel cell, which could be used to calculate both bulk and catalyst surface concentrations of the reactant gases.

\section{Anode Computational Model}

The anode is divided into three sections: the gas channel, the gas diffusion layer, and the catalyst layer. Hydrogen gas is supplied to the anode via the anode gas channel. Hydrogen gas diffuses from the gas channel through the gas diffusion layer to the catalyst layer. As the hydrogen gas reaches the catalyst, the hydrogen gas ionizes in the presence of the platinum electrode releasing electrons ( $\left.\mathrm{e}^{-}\right)$and hydrogen ions $\left(\mathrm{H}^{+}\right)$. Given that this treatment is one dimensional the gas channel is not modeled, and the reactant gases are assumed to be ideal gases.

The Navier-Stokes equations were used to model. The velocity given in the continuity equation for gas diffusion layer and catalyst layer is the filtration velocity (u). The filtration velocity is calculated based on the current density requirement. For a given pressure, the filtration velocity 
varies linearly with the current density. Because the gas is assumed to be an ideal gas, the ideal gas law is used to calculate the filtration velocity at different pressures.

The Darcy equation is used to calculate the differential pressure $(\Delta \mathrm{P})$ across the gas diffusion layer and catalyst layer for a give current density $[2,3]$ as follows:

$$
\frac{\Delta P}{\Delta x}=-\frac{\mu}{K} u
$$

The permeability $(\mathrm{K})$ of the gas diffusion layer is $1.12 \times 10^{-14} \mathrm{~m}^{2}[4,5]$.

The two primary chemical species present within the anode are hydrogen gas and water vapor. The hydrogen species equation is given by the following [6]:

$$
\varepsilon \frac{\partial C_{H_{2}}}{\partial t}+\frac{\partial\left(u C_{H_{2}}\right)}{\partial x}=\frac{\partial}{\partial x}\left(D_{e} \frac{\partial\left(C_{H_{2}}\right)}{\partial x}\right)+S_{H_{2}}
$$

$\mathrm{S}_{\mathrm{H}_{2}}$ is a consumption term, which only appears in the species equation for the catalyst layer. Hydrogen is being consumed within the catalyst layer according to:

$$
S_{H_{2}}=-\frac{i}{2 F}
$$

The water species equation is given by the following [6]:

$$
\varepsilon \frac{\partial C_{\mathrm{H}_{2} \mathrm{O}}}{\partial t}+\frac{\partial\left(u C_{\mathrm{H}_{2} \mathrm{O}}\right)}{\partial x}=\frac{\partial}{\partial x}\left(D_{e} \frac{\partial\left(C_{\mathrm{H}_{2} \mathrm{O}}\right)}{\partial x}\right)
$$

The effective diffusivity of species $i\left(D_{e, i}\right)$, used in the aforementioned species equations, is a function of the binary diffusion coefficient $\left(\mathrm{D}_{\mathrm{AB}}\right)$, the porosity $(\varepsilon)$, the tortuosity $(\tau)$, and the constriction factor $(\sigma)[7]$.

$$
D_{e, i}=D_{A B} \frac{\varepsilon \sigma}{\mathrm{T}}
$$

The constriction factor $(\sigma)$, the tortuosity $(\mathrm{T})$, and the porosity $(\varepsilon)$ were held constant for all simulations: $\sigma=0.8, \mathrm{~T}=3.0$, and $\varepsilon=0.40$ [7].

Because each of the aforementioned equations of motion must be solved simultaneously, the following vector equation is used to solve the computational domain [8].

$$
\frac{\partial U}{\partial t}+\frac{\partial E}{\partial x}=H
$$

The vector $\mathrm{U}$ for the anode is given by the following:

$$
U=\left[\begin{array}{c}
\varepsilon \rho \\
\varepsilon C_{\mathrm{H}_{2}} \\
\varepsilon C_{\mathrm{H}_{2} \mathrm{O}}
\end{array}\right]
$$


The vector $\mathrm{E}$ for the anode is given by the following:

$$
E=\left[\begin{array}{c}
\rho u \\
u C_{\mathrm{H}_{2}}-D_{e, \mathrm{H}_{2}} \frac{\partial}{\partial x}\left(C_{\mathrm{H}_{2}}\right) \\
u C_{\mathrm{H}_{2} \mathrm{O}}-D_{e, \mathrm{H}_{2} \mathrm{O}} \frac{\partial}{\partial x}\left(C_{\mathrm{H}_{2} \mathrm{O}}\right)
\end{array}\right]
$$

Because no reaction takes place within the gas diffusion layer, the vector $\mathrm{H}$ is given by the zero vector in the gas diffusion layer for both the anode and the cathode computational models:

$$
H_{G D L}=\left[\begin{array}{l}
0 \\
0 \\
0
\end{array}\right]
$$

However, in the anode catalyst layer, the vector $\mathrm{H}$ is non-zero. Because of the reaction that takes place within the catalyst layer, the vector $\mathrm{H}$ is given by the following, which includes the hydrogen gas consumption term:

$$
H_{C L}=\left[\begin{array}{c}
0 \\
-\frac{i}{2 F} \\
0
\end{array}\right]
$$

The negative sign in the aforementioned equation denotes the consumption of hydrogen gas.

A material balance is made over the anode catalyst layer. The material balance is a sum of the system inputs and generation terms minus the system outputs and consumption terms. At steady state, there are no reactions within the gas diffusion layer; therefore, both the generation term and the consumption terms are identically zero.

The input term is the flux of hydrogen at the gas diffusion layer-catalyst layer (DC) interface:

$$
\text { Input }=\frac{\rho u}{M_{H_{2}}}-\left.D_{e, D C} \frac{\partial C_{H_{2}}}{\partial x}\right|_{D C}
$$

$\mathrm{D}_{\mathrm{e}, \mathrm{DC}}$ is the effective diffusivity. The output term is the flux of hydrogen at the catalyst layermembrane layer $(\mathrm{CM})$ interface as:

$$
\text { Output }=-\left.D_{e, C M} \frac{\partial C_{H_{2}}}{\partial x}\right|_{C M}
$$

The consumption term is the reaction term (Equation 16).

$$
\text { Consumption }=\frac{i}{2 F}
$$

The variable $\mathrm{i}$ is the current density, and F is Faraday's constant. 
The flux of hydrogen into the catalyst layer is equal to the flux of hydrogen gas out of the catalyst layer plus all of the hydrogen consumed within the catalyst layer. Because the diffusivity of hydrogen gas within the gas diffusion layer and the diffusivity of hydrogen gas within the catalyst layer are six orders of magnitude greater than the diffusivity of hydrogen within the polymer membrane, the output (Equation 15) can be neglected. Moreover, since the convective term in the input term (Equation 14) is larger than the diffusive term, the diffusive term is negligible. Therefore,

$$
\frac{\rho u}{M_{H_{2}}}=\frac{i}{2 F}
$$

Specifically, very little hydrogen gas diffuses across the polymer membrane. The diffusivity of hydrogen within the gas diffusion layer and catalyst layer is approximately $1.1028 \times 10-4 \mathrm{~m} 2 / \mathrm{s}$ [4]; however, the diffusivity within the membrane is approximately $2.59 \times 10-10 \mathrm{~m} 2 / \mathrm{s} \mathrm{[4].}$

\section{Cathode Computational Model}

The cathode is also divided into three sections: the gas channel, the gas diffusion layer, and the catalyst layer. There are three chemical species present in the cathode gas diffusion layer: oxygen gas, nitrogen gas, and water. Oxygen gas $\left(\mathrm{O}_{2}\right)$ is supplied to the gas diffusion layer from the gas channel. Nitrogen is present if oxygen is supplied via ambient air. Unlike nitrogen and oxygen, water $\left(\mathrm{H}_{2} \mathrm{O}\right)$ is present in two phases. However, this model assumes that water exists only in a supersaturated vapor phase $[5,10]$. Since this model is isothermal, little is lost by making this assumption.

The dynamics of the cathode gas diffusion layer is described using the transport equations. There are three species present within the cathode: oxygen gas, nitrogen gas, and water vapor. However, this treatment assumes that the effect of nitrogen on the system can be neglected; therefore, there are only two cathode species equations [6]: For oxygen as:

$$
\varepsilon \frac{\partial C_{O_{2}}}{\partial t}+\frac{\partial\left(u C_{O_{2}}\right)}{\partial x}=\frac{\partial}{\partial x}\left(D_{e, O_{2}} \frac{\partial\left(C_{O_{2}}\right)}{\partial x}\right)+S_{O_{2}}
$$

Because oxygen is being consumed within the catalyst layer, a consumption source term $\left(\mathrm{S}_{\mathrm{O}_{2}}\right)$ is added to the oxygen species equation as:

$$
S_{O_{2}}=-\frac{i}{4 F}
$$

The cathode water species equation is given by the following [6]:

$$
\varepsilon \frac{\partial C_{\mathrm{H}_{2} \mathrm{O}}}{\partial t}+\frac{\partial\left(u C_{\mathrm{H}_{2} \mathrm{O}}\right)}{\partial x}=\frac{\partial}{\partial x}\left(D_{e, \mathrm{H}_{2} \mathrm{O}} \frac{\partial\left(C_{\mathrm{H}_{2} \mathrm{O}}\right)}{\partial x}\right)+S_{\mathrm{H}_{2} \mathrm{O}}
$$

A generation source term $\left(\mathrm{S}_{\mathrm{H}_{2} \mathrm{O}}\right)$ is added to the water species equation as:

$$
S_{\mathrm{H}_{2} \mathrm{O}}=\frac{2 i}{4 F}
$$


Water is being generated within the catalyst layer. There are no reactions within the gas channel or the gas diffusion layer. Therefore, in these regions $\mathrm{S}_{\mathrm{H}_{2} \mathrm{O}}$ is zero.

The explicit MacCormack scheme is used to solve each of the differential equations. The explicit MacCormack scheme was selected because of the ease of computation relative to implicit schemes, and the MacCormack scheme is a second order accurate explicit scheme [8, 9]. The method is second order accurate in both space and time [8].

\section{Fuel Cell Irreversibilities}

Although it is extremely important to understand the physics of fuel cell systems, it is equally important to understand the electrolytic processes, which are the backbone of the PEM fuel cell. As previously stated, hydrogen gas $\left(\mathrm{H}_{2}\right)$ and oxygen gas $\left(\mathrm{O}_{2}\right)$ react in the presence of a platinum electrode to generate electrical energy (Equation 1).

Because of irreversibilities, the actual voltage of a PEM fuel cell is much less than the open circuit voltage $\left(\mathrm{E}^{\mathrm{o}}\right)$. Fuel cell systems, like all real systems, experience losses. There are four major losses associated with fuel cell systems: activation losses $\left(\mathrm{V}_{\text {act }}\right)$, ohmic losses $\left(\mathrm{V}_{\text {ohm }}\right)$, concentration losses $\left(\mathrm{V}_{\text {conc }}\right)$, and parasitic losses $\left(\mathrm{V}_{\mathrm{P}}\right)$ [11]. Hence, the cell voltage can be estimated as:

$$
E_{\text {cell }}=E^{o}-V_{\text {act }}-V_{\text {ohm }}-V_{\text {conc }}-V_{p}
$$

The Tafel equation (Equation 23) was used to estimate the activation losses associated with the PEM fuel cell.

$$
V_{a c t}=a \ln \left(\frac{i}{i_{o}}\right)
$$

Where $\mathbf{a}$ is a expirical parameter, $\mathbf{i}$ is the current density, and $\mathbf{i}_{\mathbf{0}}$ is the exchange current density. The exchange current density $\left(i_{\mathrm{o}}\right)$ is the current density which flows with equal magnitude in both directions at equilibrium [11]. A typical value for the exchange rate current density is 0.67 $\mathrm{A} / \mathrm{m}^{2}$, and a typical value for the empirical constant $\mathbf{a}$ is $0.06 \mathrm{~V}$. [12, 13]

A fuel cell is the voltage source of an electrical circuit, and, like other voltage sources, fuel cells have internal resistances which serve to reduce the overall voltage of the fuel cell. The ohmic losses that are common to fuel cells also follow Ohm's Law accordingly:

$$
V_{\text {ohmic }}=i R_{O h m}
$$

The fuel cell's resistance $\left(\mathrm{R}_{\mathrm{Ohm}}\right)$ is function of the membrane thickness $\left(\mathrm{t}_{\mathrm{m}}\right)$ and the membrane water content $\left(\sigma_{\mathrm{m}}\right)$ and can be represented as:

$$
R_{\text {Ohm }}=\frac{t_{m}}{\sigma_{m}}
$$

The membrane water content is a function of the fuel cell's temperature and the saturation of the fuel cell $\left(\lambda_{\mathrm{m}}\right)$ as follow: 


$$
\begin{aligned}
& \sigma_{m}=b_{1} \exp \left[b_{2}\left(\frac{1}{303}-\frac{1}{T_{f c}}\right)\right] \\
& b_{1}=0.005139 \lambda_{m}-0.00326
\end{aligned}
$$

The saturation $\left(\lambda_{\mathrm{m}}\right)$ is 14 at $100 \%$ saturation, and saturation $\left(\lambda_{\mathrm{m}}\right)$ is zero at $0 \%$ saturation [16]. As the equation suggests, the greater the saturation, the lower the polymer membrane resistance.

Concentration losses $\left(\mathrm{V}_{\text {conc }}\right)$ occur because of difference in concentration between the concentration in the bulk or interstitial space surrounding the catalyst active site and the concentration of reactant at the electrode surface [15]. The reactions are surface catalyzed reaction and reactant reacts on the surface of the catalyst. There are losses associated with this surface level reaction. To account for these losses, the following mathematical model was suggested to model the concentration losses [16].

$$
V_{\text {conc }}=i\left(c_{2} \frac{i}{i_{\max }}\right)^{2}
$$

The parameter " $\mathrm{i} \max$ " is the current density that causes precipitous voltage drop [16]. For pressure less than 2 bar, the coefficient $C_{2}$ is given by the following expression [16].

$$
C_{2}=\left(0.000716 T_{f_{c}}\right) F(P)-0.00145 T_{f_{c}}+1.68
$$

Where:

$$
\begin{aligned}
& F\left(P_{O_{2}}, P_{\text {sat }}\right)=\left(\frac{P_{O_{2}}}{0.1173 \times P_{\text {Total }}}+P_{\text {sat }}\right) \\
& \ln \left(P_{\text {sat }}\right)=77.3450+0.0057 T-\frac{7235}{T^{8.2}}
\end{aligned}
$$

The saturation pressure of water is in units of Pascals and the temperature is Kelvin.

Parasitic loss $\left(\mathrm{V}_{\mathrm{p}}\right)$ refers to the loss of voltage potential due to unwanted reactions. The most common parasitic loss is due to fuel crossover [17]. The flux of hydrogen gas associated with hydrogen migration across the polymer membrane is calculated using the Fick's Law as:

$$
\left.N_{H_{2}}\right|_{\text {Membrane }}=D_{H_{2}} \frac{d C_{H_{2}}}{d x} \approx D_{H_{2}}\left(\frac{\left.C_{H_{2}}\right|_{\text {Anode }}}{\Delta x}\right)
$$

The diffusivity of hydrogen $\left(\mathrm{D}_{\mathrm{H}_{2}}\right)$ within the membrane is $2.59 \times 10^{-10} \mathrm{~m}^{2} / \mathrm{s}$ [4]. Using the hydrogen flux from the aforementioned equation, the current density deficit associated with this migrating hydrogen is calculated (Equation 33):

$$
i_{\text {def }}=\left.2 N_{H_{2}}\right|_{\text {Membrane }}
$$


The current density deficit $\left(i_{\text {def }}\right)$ is twice the hydrogen flux, because two electrons are liberated with hydrogen gas dissociates in the presence of the catalyst. Using the current density deficit and the reference exchange current density, the parasitic loss is calculated [14] as:

$$
V_{p}=-\frac{R T}{0.5 F} \ln \left(\frac{i_{d e f}}{i_{o}}\right)
$$

The exchange current density $\left(\mathrm{i}_{\mathrm{o}}\right)$ is a function of the pressure [14] and could be presented as:

$$
i_{o}=i_{o}^{r e f}\left(\frac{P}{P_{o}}\right)^{\frac{C_{P}}{C_{v}}}
$$

\section{Results and Discussion}

One dimensional (1-D) models were constructed which calculated the concentration of reactant at different gas channel pressures. Both the anode and cathode were modeled. The dimensions of the modeled fuel cell are presented in Table 1.

Table 1: Micro PEM fuel cell model dimensions

\begin{tabular}{|c|c|c|c|}
\hline & $\begin{array}{c}\text { Gas } \\
\text { Gas Channel } \\
\text { (microns) }\end{array}$ & $\begin{array}{c}\text { Diffusion } \\
\text { Layer } \\
\text { (microns) }\end{array}$ & $\begin{array}{c}\text { Catalyst } \\
\text { Layer } \\
\text { (microns) }\end{array}$ \\
\hline Anode & 50 & 50 & 5 \\
\hline Cathode & 50 & 50 & 5 \\
\hline
\end{tabular}

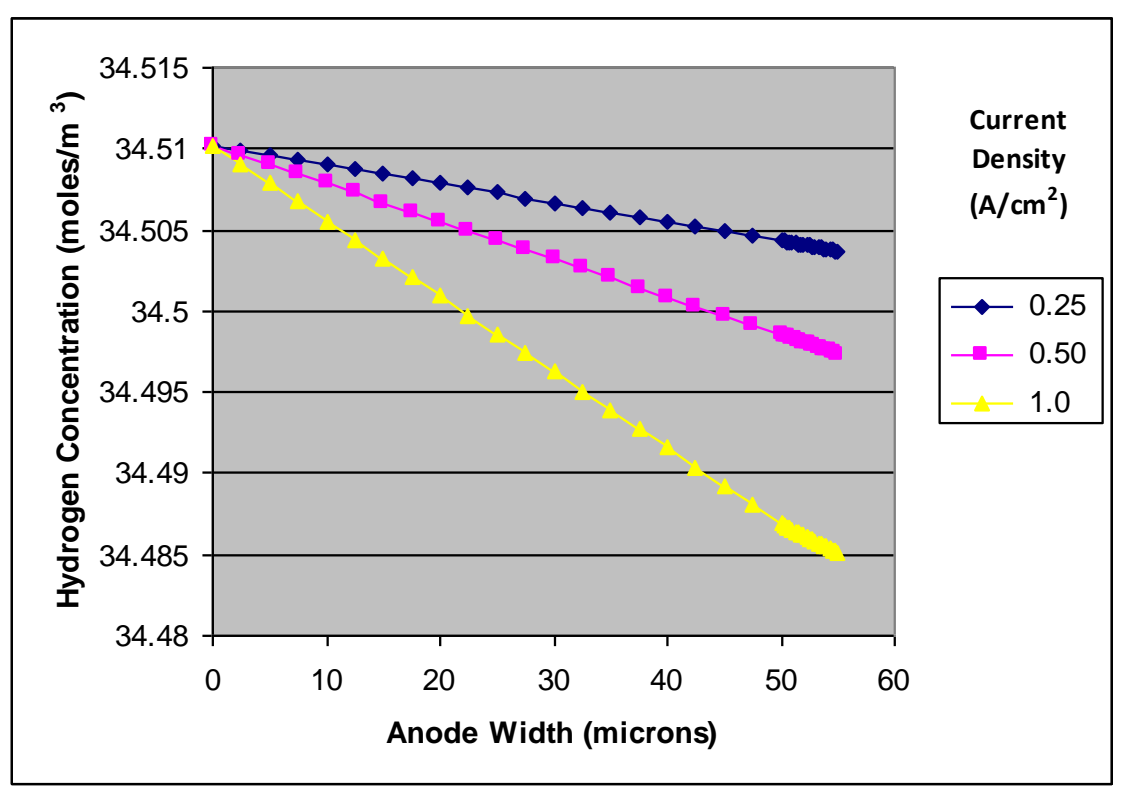

Figure 2: Anode Hydrogen Concentration (System Pressure = 1 bar) 


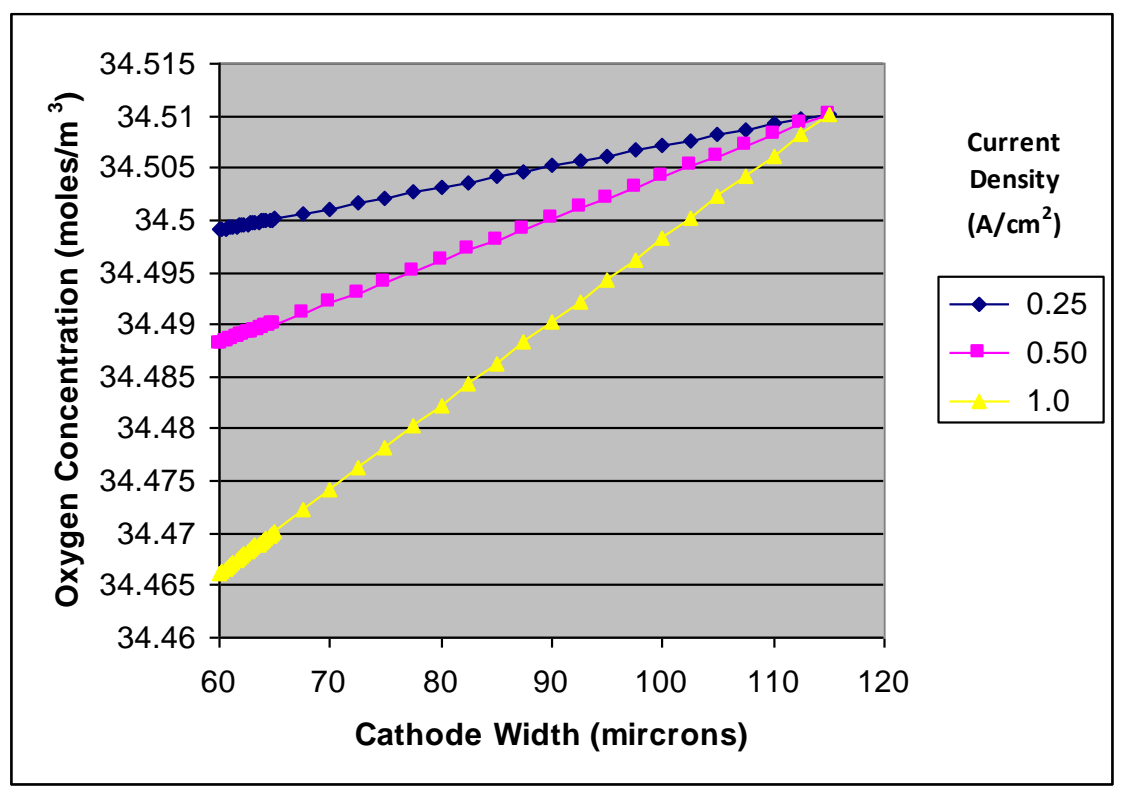

Figure 3: Cathode Oxygen Concentration (System Pressure = 1 bar)

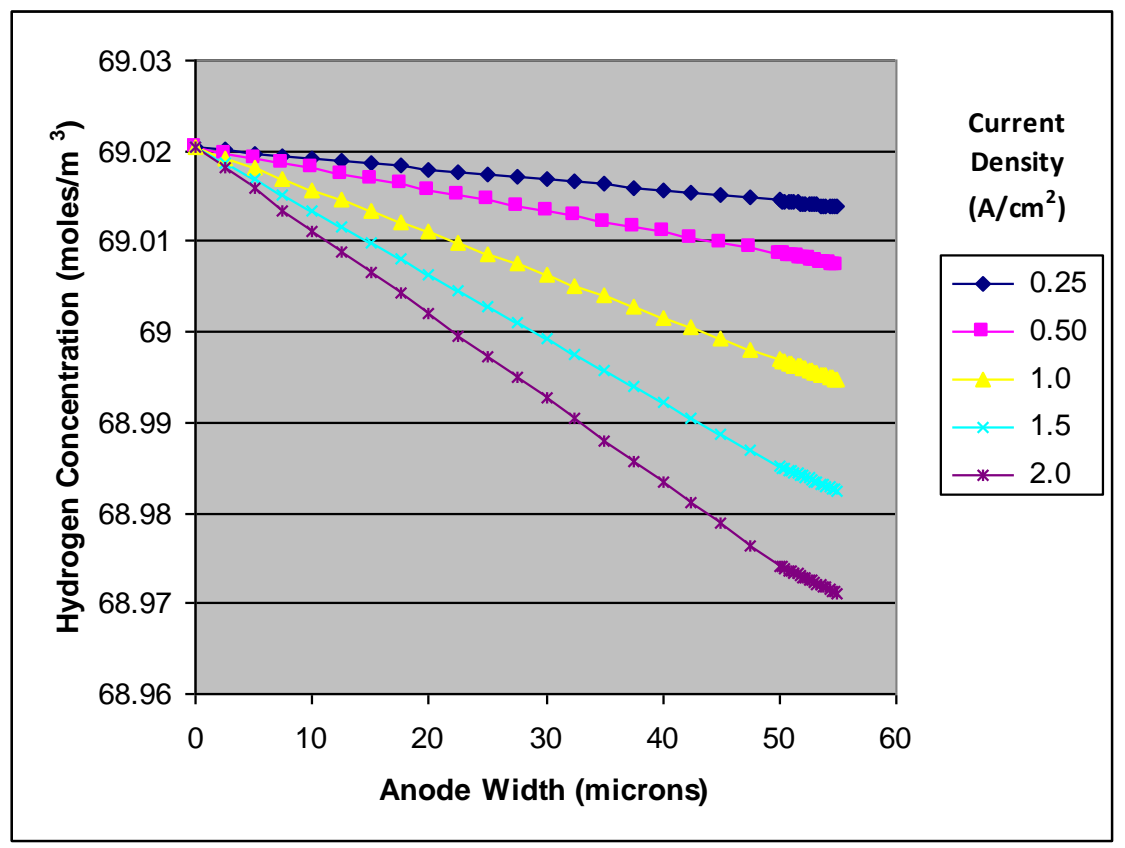

Figure 4: Anode Hydrogen Concentration (System Pressure $=2$ bar)

Figures 2 through 5 show the data calculated for the 1-D cases at a variety of pressures and current densities. Data show that the concentration of reactant in the anode and cathode electrodes is decreasing though small from channel to the membrane with increasing the current density as expected. 


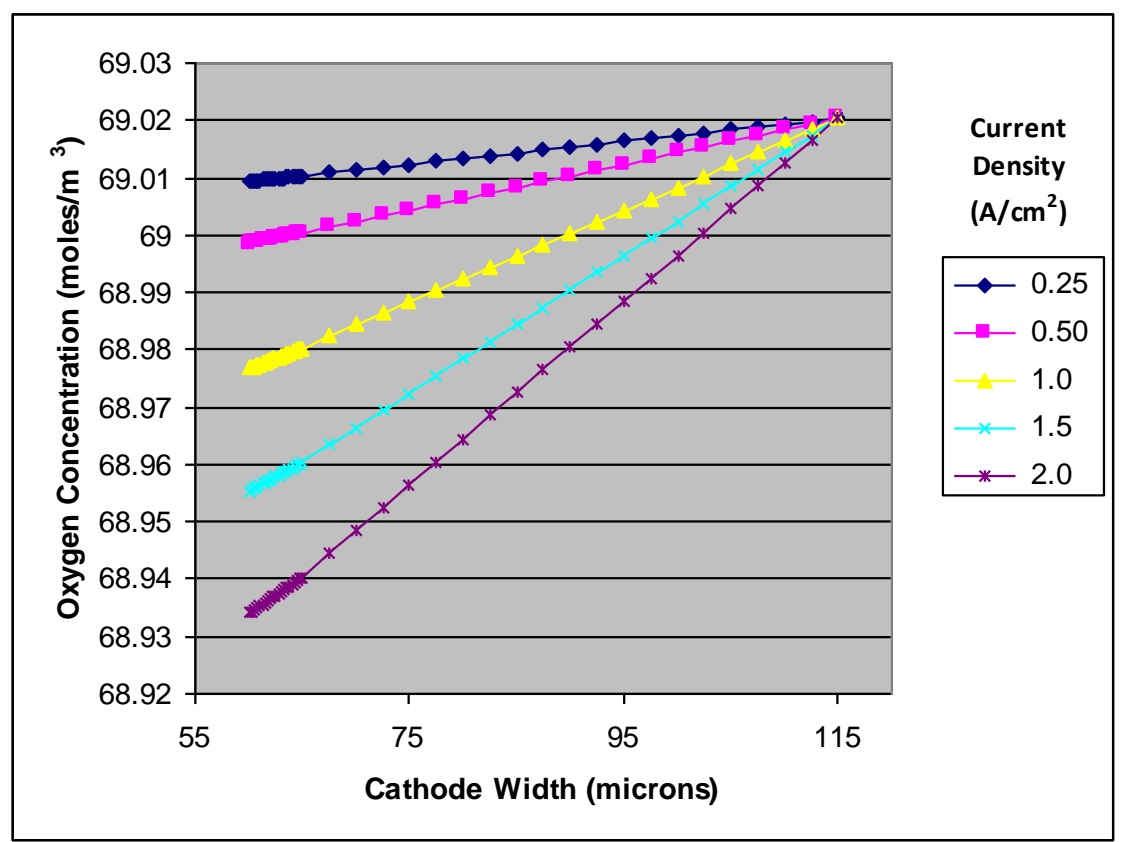

Figure 5: Cathode Oxygen Concentration (System Pressure $=2$ bar)

As mentioned earlier, one of the prevailing hypotheses is that the hydrogen and oxygen concentrations at the catalyst layer-membrane layer interfaces are zero. However, the data in these figures show that the bulk concentration of reactant at the catalyst layer-membrane layer interface is not zero. The aforementioned assumption ignores the fact that the reaction in PEM fuel cells occurs at the surface of the catalyst, and not in the bulk.

The results suggest that the reactant deficit experienced at high current densities is localized to the catalyst surface. Barbir (2005) furthers to the catalyst surface as the active site [14]. The active site is where the reaction actually occurs. When the current density reaches the limiting current density, the active site is being starved of reactant. Specifically, reactant is supplied at the same rate at which the reactant is consumed. There is a mass transfer resistance, which is established around the active site, and, as the current density increase, the rate of mass transfer to the active site is insufficient to maintain the forward reaction. This attempts to explain that localized starvation of the active sites is the cause of the sudden drop in the voltage at the limiting current density. More specifically, a resistance is established around the active site and the time constant required for the migration of reactant to the active site is much less than the time constant associated with the reaction at the active site at higher current densities. Forment \& Bischoff (1990) and Fogler (1992) discuss the phenomenon of surface catalysis. The consumption of reactants (hydrogen or oxygen) at the catalyst active site interface, i.e. on the surface of the catalyst, has to be compensated for by transport from the bulk fluid [7, 18].

Prior to reaching the limiting current density, the reactant gases are supplied at rate greater than the reaction rate at the catalyst surface. However, when the current density reaches, the limiting current density, the process is limited by the kinetics of the reaction. Specifically, there are insufficient active sites for the current density to increase; therefore, at this point of saturation, the current density is limited. 
Prior to reaching the limiting current density, the mass transfer step is much faster than the surface reaction; thus, the reactant concentration $\left(\mathrm{C}_{\mathrm{A}_{\mathrm{i}}}\right)$ at the surface is the same as the concentration $\left(\mathrm{C}_{\mathrm{A}}\right)$ measured in the bulk in the catalyst layer. However, when the current density exceeds the limiting current density, the rate of mass transfer through the mass transfer layer surrounding the active site is much slower than the rate of reaction. The following equation is used to describe the flux of reactant $\left(\mathrm{N}_{\mathrm{A}}\right)$ across the mass transfer layer within the catalyst layer.

$$
N_{A}=k_{g}\left(C_{A}-C_{A_{i}}\right)
$$

At the limiting current density, the rate of mass transfer equals the rate of reaction. Therefore, the reactant gases cannot be supplied fast enough to allow the reaction to proceed at or above the limiting current density [18]. Hence, increasing catalyst dispersion and catalyst surface within the catalyst layer should increase the limiting current density.

Although the concentration is not zero at the membrane-catalyst layer interface, the current density is not allowed to increase without bound. One reason for the limitation on the current density is the balance between reaction kinetics and mass transport. The dissociation of hydrogen gas into hydrogen ions and two electrons only occurs at specific active sites at the surface of the catalyst. Although the anode and cathode are typically depicted with defined layers, the reality is that both are a web of small channels, similar to capillaries. The gas channel is integrated within the gas diffusion layer, and the gas diffusion layer directs the reactant gases toward active sites in the catalyst layer. These active sites are special. In order for the forward reaction to occur, the reactant gas must be in contact with the platinum catalyst and the platinum catalyst must be in contact with the membrane [14]. It is this triple point, which is essential. When the active sites are saturated, the current density cannot increase. At the limiting current density, neither the bulk oxygen concentration nor the bulk hydrogen concentration is zero at the catalyst layer-membrane interface.

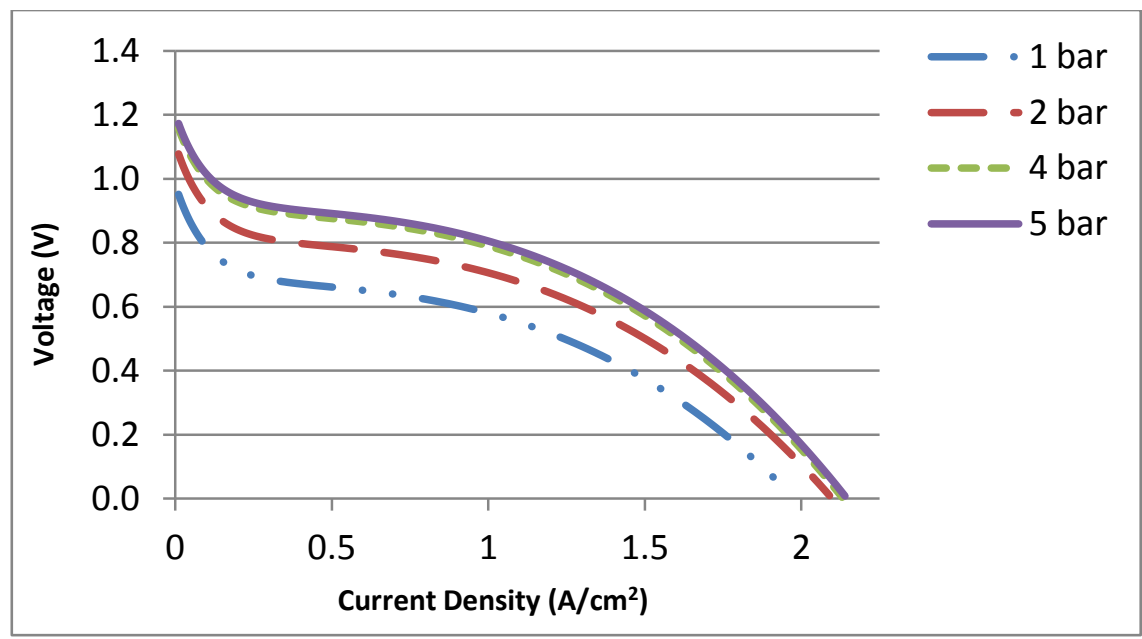

Figure 6: Polarization Curve PEM fuel cell (Membrane Thickness = 5 microns) 
The polarization curve for the 1-D PEM fuel cell case calculated using the model is presented below in Figure 6 for various pressures within the anode and cathode gas channels as a typical example.

As mentioned earlier, prior to reaching the limiting current density, the mass transfer step is much faster than the surface reaction. As long as the current density is lower than the limiting current density, the surface concentration will be something greater than zero. This treatment attempts to predict the concentration at the surface of the catalyst by using the bulk concentration and the boundary conditions.

At lower current densities, the surface concentration will be very close to the bulk concentration of reactant; however, when the current density exceeds the limiting current density, the rate of mass transfer through the mass transfer diffusion layer surrounding the active site is much slower than the rate of reaction. For this reason at the limiting current density, the reaction is prevented from exceeding the limiting current density. The following equation is used to describe the flux of reactant $\left(\mathrm{N}_{\mathrm{A}}\right)$ across the mass transfer diffusion layer.

$$
N_{H_{2}}=\frac{i}{n F}=j
$$

The flux $\left(\mathrm{N}_{\mathrm{H}_{2}}\right)$ of reactant across the mass diffusion layer is proportional to the concentration difference between the bulk concentration $\left(\mathrm{C}_{\mathrm{H}_{2} \text {,Bulk }}\right)$ and the catalyst surface concentration $\left(\mathrm{C}_{\mathrm{H}_{2} \text {,Surface }}\right)$. The mass transfer coefficient $\left(\mathrm{k}_{\mathrm{g}}\right)$ is the "constant" of proportionality.

$$
N_{H_{2}}=k_{g}\left(C_{H_{2}, \text { Bulk }}-C_{H_{2}, \text { Surface }}\right)
$$

In heterogeneous catalysis, the reaction does not occur within the bulk; rather the reaction occurs at the surface of the catalyst, so it is the catalyst surface concentration that is important, not the bulk concentration. By equating Equations 38 and 39, the $\mathrm{kg}$ can be expressed as:

$$
k_{g}=\frac{i}{n F} \times \frac{1}{\left(C_{H_{2}, \text { Bulk }}-C_{H_{2}, \text { Surface }}\right)}
$$

This model assumes that at the limiting current density $\left(\mathrm{i}_{\mathrm{L}}\right)$ that the concentration of reactant at the catalyst surface is zero. Secondly, the catalyst surface concentration at $i=0 \mathrm{~A} / \mathrm{cm}^{2}$ is assumed to be the bulk concentration. Using the value for the mass transfer coefficient calculated for the limiting current density case, the other surface concentrations were calculated and illustrated in Figures 7 and 8 for two different pressure values as examples. 


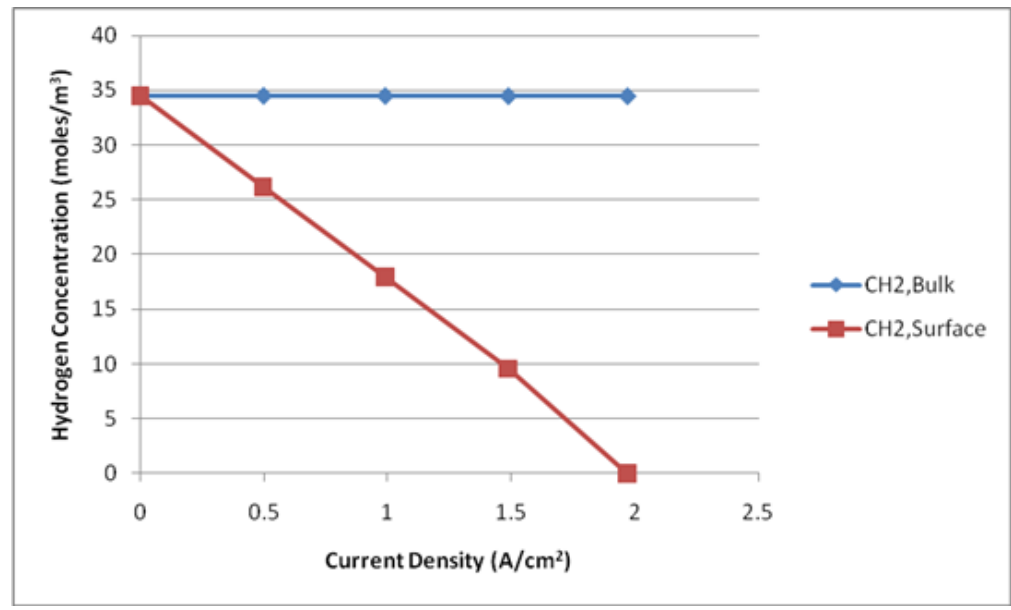

Figure 7: Anode Hydrogen Concentration vs. Current Density (Pressure = 1 bar)

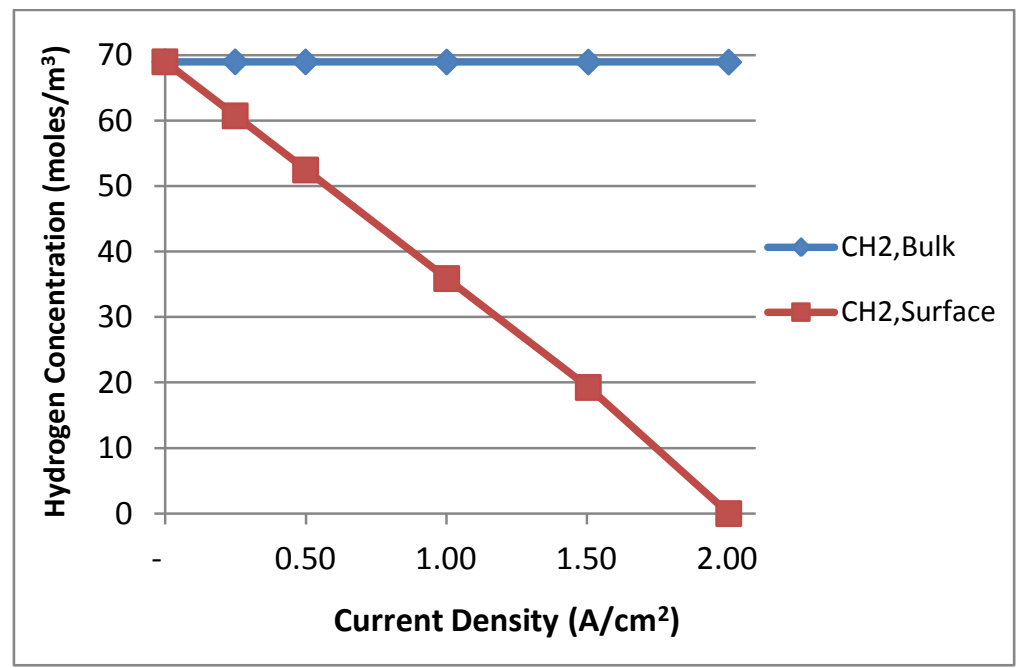

Figure 8: Anode Hydrogen Concentration vs. Current Density (Pressure $=2$ bar)

The mass transfer coefficients for each of the aforementioned pressure scenarios were plotted for both the anode and the cathode in Figure 9 and 10 respectively. 


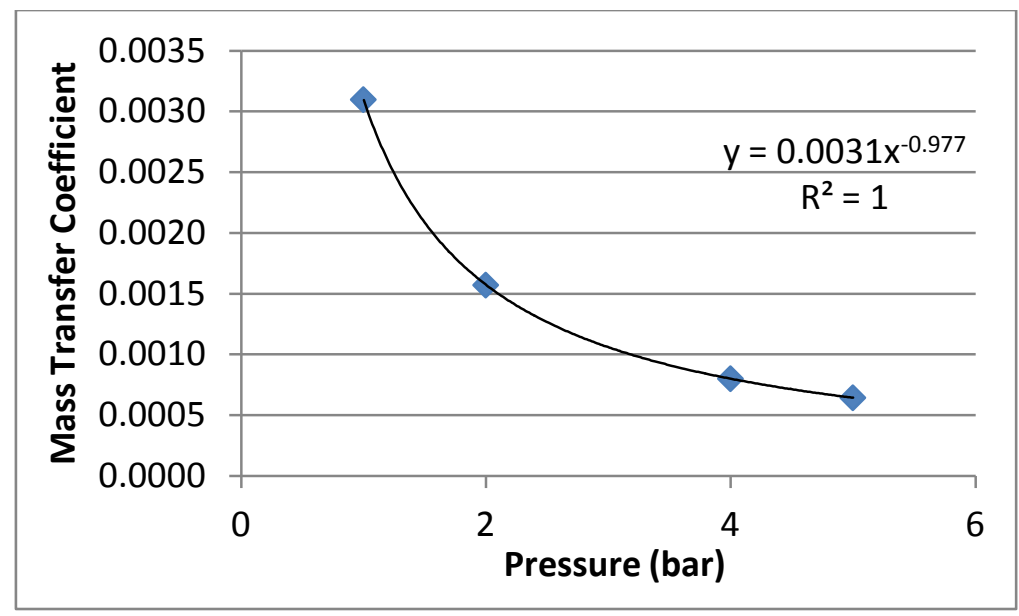

Figure 9: Anode Mass Transfer Coefficient vs. Pressure



Figure 10: Cathode Mass Transfer Coefficient vs. Pressure

Although prior fuel cell models indirectly discuss the impact of concentration on activation losses and concentration losses, this treatment links explicitly the fuel cell overpotentials and the movement of reactants within the PEM fuel cell system. This treatment relates between the bulk concentration and the surface concentration, which is key to calculating the activation overpotential and the concentration overpotential.

The results from the 1-D model also were compared to the data from [19] of the Imperial College of London and presented in Figure 11. The data show that both models predict reactant concentration at the catalyst layer-membrane layer interface. In addition, the change in concentration for the two models is approximately the same order of magnitude.

Figure 12 shows the data from [19] and the 1-D model data. The figure shows that there is relatively good agreement between the two data sets. 


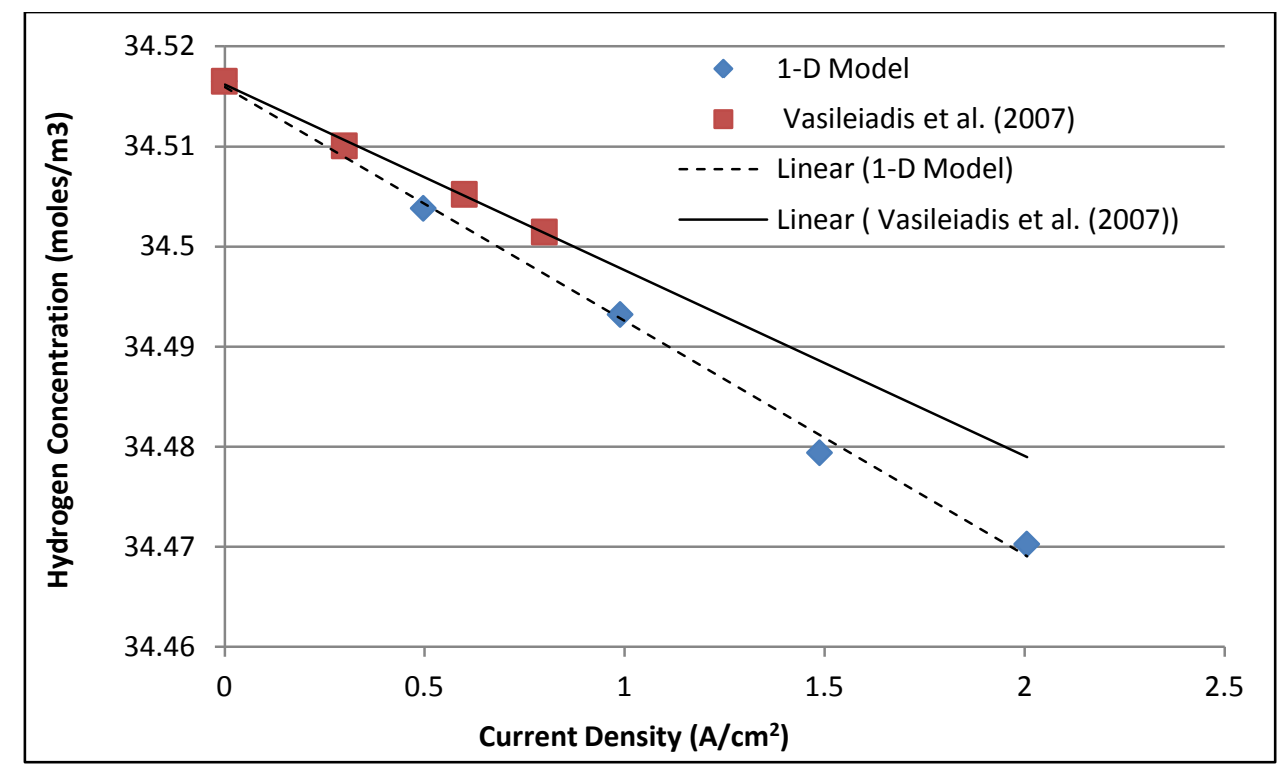

Figure 11: Comparison of Vasileiadis et al. (2007) Model \& 1-D Model Data.

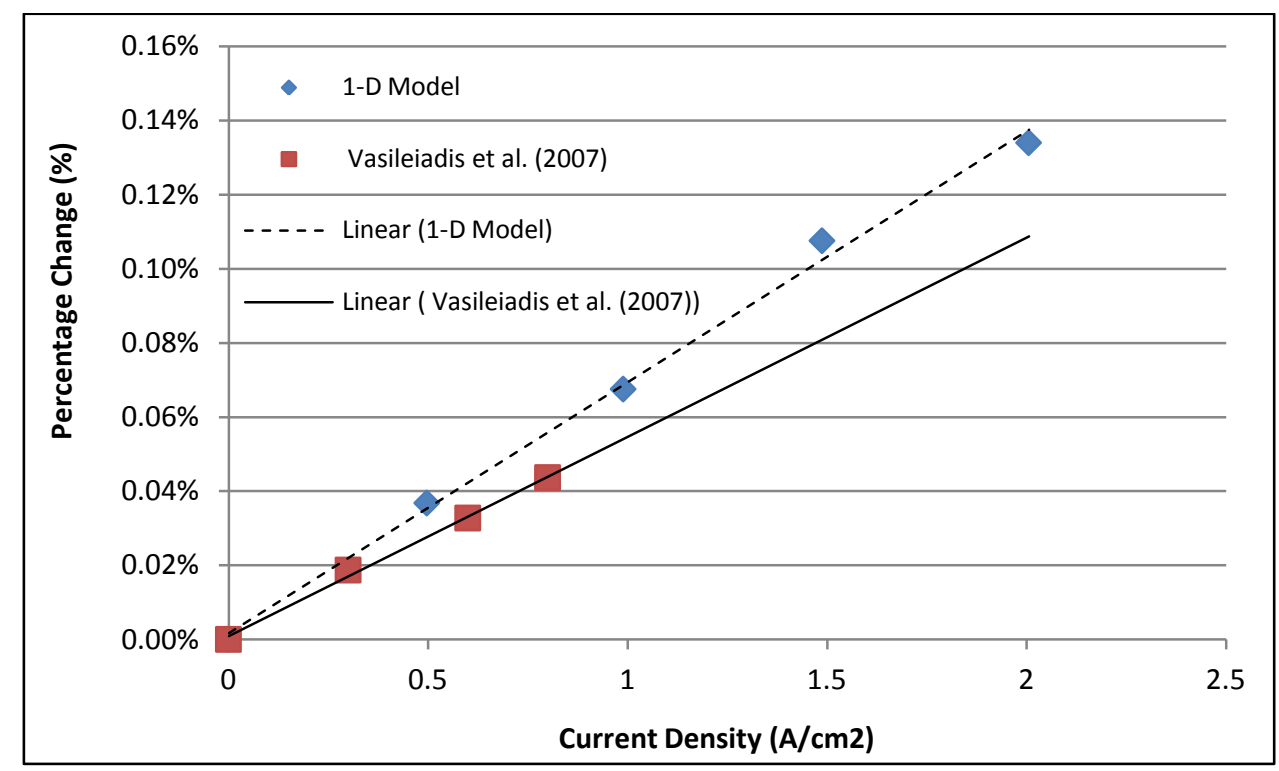

Figure 12: Percentage Change of Vasileiadis et al. (2007) Model \& 1-D Model.

\section{Conclusion}

Polymer Electrolyte Membrane (PEM) fuel cell systems are heterogeneous catalytic systems. The model described was used to simulate the catalyst surface concentration of reactant gases at the catalyst layer-membrane layer inteface and the data showed that the bulk concentration of reactant at the catalyst layer-membrane interface is not zero at the limiting current density as expected though the surface concentration of reactant that goes to zero at the limiting current density. 
This treatment defined the link between the reactant transport within fuel cell systems and the overpotentials, and clearly established a method of relating the concentration gradients within the PEM fuel cell with the activation overpotential and concentration overpotentials.

\section{Nomenclature}

$\mathrm{D}_{\mathrm{e}, \mathrm{i}} \quad$ Effective Diffusivity of Species i $\left(\mathrm{m}^{2} / \mathrm{s}\right)$

i Current Density

P Pressure

F Faraday's Constant

K Permeability $\left(\mathrm{m}^{2}\right)$

$\mathrm{M}_{\mathrm{i}} \quad$ Molecular Weight of Species i

$\mathrm{C}_{\mathrm{i}} \quad$ Concentration of Species i

$\mathrm{D}_{\mathrm{AB}} \quad$ Binary Diffusivity

S Generation or Consumption Source Term

GDL Gas Diffusion Layer

CL Catalyst Layer

GC Gas Channel

R Universal Gas Constant

$\mathrm{T}_{\mathrm{fc}} \quad$ Fuel Cell Temperature

$\mathrm{T}_{\mathrm{w}} \quad$ Wall Temperature

Mem Membrane

$\mathrm{A}_{\mathrm{DC}}$ Cross Sectional Area at GDL-CL Interface

$\mathrm{A}_{\mathrm{CM}} \quad$ Cross Sectional Area at CL-MEM Interface

$\mathrm{N}_{\mathrm{i}} \quad$ Flux of species $\mathrm{i}$

$\mathrm{k}_{\mathrm{g}} \quad$ mass transfer coefficient

$\rho \quad$ Density $\left(\mathrm{kg} / \mathrm{m}^{3}\right)$

$\varepsilon \quad$ Porosity

$\sigma \quad$ Constriction Factor

$\tau \quad$ Tortuosity

$\mu \quad$ Viscosity

$\sigma_{\mathrm{v}} \quad$ Tangential Momentum Accommodation Coefficient

$\gamma \quad$ Ratio of Specific Heats $(\mathrm{Cp} / \mathrm{Cv})$

$\tau_{\mathrm{s}} \quad$ Viscous Stress Component 


\section{References}

[1] Fauvarque, J. (2001). Les piles à combustible et leurs applications, Annales De Chimie Science Des Matériaux, 26 (4), 1-8.

[2] Vorobev, A., Zikanov, O., and Shamin, T. (2007). A computational model of a PEM fuel cell with finite vapor absorption rate, Journal of Power Sources, 166, 92-103.

[3] Hwang, J. J., Chao, C. H., Chang, C. L., Ho, W. Y., and Wang, D. Y. (2007). Modeling of two-phase temperatures in a two-layer porous cathode of polymer electrolyte fuel cells, International Journal of Hydrogen Energy, 32, 405-414.

[4] Ju, H., and Wang, C. (2004). Experimental Validation of a PEM Fuel Cell Model by Current Distribution Data, Journal of the Electrochemical Society, 151 (11), A1954-A1960.

[5] Ju, H., Meng, H., and Wang, H. (2005). A single-phase non-isothermal model for PEM fuel cells, International Journal of Heat and Mass Transfer, 48, 1303-1315.

[6] Skelland, A. (1974). Diffusional Mass Transfer, John Wiley \& Sons, Inc.

[7] Fogler, H. (1992). Elements of Chemical Reaction Engineering, Second Edition, Prentice Hall, Englewood Cliffs, NJ

[8] Tannehill, J. C., Anderson, D. A., and Pletcher, R. H. (1997). Computational Fluid Mechanics and Heat Transfer, Taylor \& Francis, S. Washington DC.

[9] Hoffmann, K. A. (1989). Computational Fluid Dynamics for Engineers, Engineering Education System, Austin.

[10] Springer, T., Zawodzinski, T., and Gottesfeld, S. (1991). Polymer electrolyte fuel cell model, Journal of Electrochemical Society, 138 (8), 2334-2342.

[11] Haile, S. (2003). Fuel cell materials and components, Acta Materialia, 51, 5981 - 6000.

[12] Larminie, J., and Dicks, A. (2003). Fuel Cell Systems Explained, 2nd edition, Chichester, John Wiley \& Sons LTD.

[13] Lottin, O., Antoine, B., Colinart, T., Didierjean, S., Maranzana, G., Moyne, C., et al. (2009). Modeling of the operation of polymer exchange membrane fuel cells in the presence of electrodes flooding, International Journal of Thermal Sciences, 48(1), 133-145.

[14] Barbir, F. (2005). PEM Fuel Cells: Theory and Practice, Elsevier Academic Press, Amsterdam.

[15] Oldham, K. B., and Myland, J. C. (1994). Fundamentals of Electrochemical Science, Academic Press, Inc, San Diego.

[16] Pukrushpan, J., Stefanopoulou, A., and Peng, H. (2005). Control of Fuel Cell Power Systems: Principles, Modeling, Analysis and Feedback Design, Springer, London.

[17] Kanezaki, T., Li, X., and Baschuk, J. J. (2006). Cross-leakage flow between adjacent flow channels in PEM fuel cells, Journal of Power Sources, 162(1), 415-425.

[18] Froment, G. F., and Bischoff, K. B. (1990). Chemical Reactor Analysis and Design, Second Edition, John Wiley \& Sons, New York.

[19] Vasileiadis, N., Brett, D. J. L., Vesovic, V., Kucernak, A. R., Fontes, E., and Brandon, N. P. (2007). Numerical modeling of a single channel polymer electrolyte fuel cell, Journal of Fuel Cell Science and Technology, 4, 336-344. 